\title{
Evolution of Ultra-Fine Grains in AZ31 and AZ61 Mg Alloys during Multi Directional Forging and Their Properties
}

\author{
H. Miura, X. Yang and T. Sakai \\ Department of Mechanical Engineering and Intelligent Systems, UEC Tokyo \\ (The University of Electro-Communications), Tokyo 182-8585, Japan
}

AZ31 and AZ61 Mg alloys were multi directionally forged (MDFed) during decreasing temperature from $623 \mathrm{~K}$ to $423 \mathrm{~K}$ to cumulative strain of $\Sigma \Delta \varepsilon=4.8$ by $\Delta \varepsilon=0.8$ pass strain at a strain rate of $3 \times 10^{-3} \mathrm{~s}^{-1}$. In both $\mathrm{Mg}$ alloys, the average grain size gradually decreased with increasing cumulative strain. After straining to $\Sigma \Delta \varepsilon=3.2$, i.e., after 4 passes of MDF, ultra fine grained (UFG) microstructures with average grain size of $1 \mu \mathrm{m}$ were uniformly evolved. By prolonged straining, the grains became further finer. The AZ61 Mg alloy MDFed to $\Sigma \Delta \varepsilon=4.0$ showed quite high hardness over $1.2 \mathrm{GPa}$, while that of the AZ31 Mg alloy was $850 \mathrm{MPa}$ at $\Sigma \Delta \varepsilon=4.8$. The differences of UFG evolution and mechanical behaviors during MDF of AZ 31 and AZ61 Mg alloys are precisely investigated. [doi:10.2320/matertrans.MC200737]

(Received October 18, 2007; Accepted February 8, 2008; Published March 27, 2008)

Keywords: AZ31 magnesium alloy, AZ61 magnesium alloy, ultra fine grain, severe plastic deformation, multi directional forging, superplasticity, high temperature deformation

\section{Introduction}

Numerous researches on ultra fine grained (UFGed) materials produced by severe plastic deformation (SPD) have been carried out. ${ }^{1)}$ This is because of expected excellent properties such as high strength, large plasticity and so on. Actually, SPD processes are adopted also for $\mathrm{Mg}$ alloys to modify their mechanical properties. $\mathrm{Mg}$ and $\mathrm{Mg}$ alloys are known as materials of low plasticity. Recently, Xing et al. have reported that equiaxed UFGs of $0.35 \mu \mathrm{m}$ in $\mathrm{AZ} 31 \mathrm{Mg}$ alloy can be produced by multi directional forging (MDF) during decreasing temperature condition and it exhibits superplasticity over $300 \%$ in nominal strain at $423 \mathrm{~K}^{2)}$ The UFGed AZ31 Mg alloy exhibited relatively large elongation of $20 \%$ in nominal strain and ultimate strength of $530 \mathrm{MPa}$ at room temperature. Such obvious improvement of the mechanical properties is supposed due to UFGs, in which plastic deformation is assisted by grain boundary sliding (GBS). GBS is known to take place even at room temperature in $\mathrm{Mg}$. ${ }^{3)}$

Nevertheless, further strengthening of $\mathrm{Mg}$ and $\mathrm{Mg}$ alloys as well as reduction of number of MDF processes to produce UFGs is desirable. Still more, the researches of UFGed $\mathrm{Mg}$ alloys by MDF, however, are limited only for AZ $31 \mathrm{Mg}$ alloy. The purpose of the present study is to apply the MDF process to AZ61 Mg alloy to obtain further strengthened $\mathrm{Mg}$ alloy.

\section{Experimental}

Samples of AZ31 and $61 \mathrm{Mg}$ alloys with initial grain sizes of $22.3 \mu \mathrm{m}$ and $38.5 \mu \mathrm{m}$ were MDFed during decreasing temperature from $623 \mathrm{~K}$ to $423 \mathrm{~K}$ in vacuum on an Instrontype mechanical testing machine at an initial strain rate of $3 \times 10^{-3} \mathrm{~s}^{-1}$. The dimension of the sample was $31 \times 21 \times$ $14 \mathrm{~mm}^{3}$. The method of the MDF and the temperature profiles are schematically described in Figs. 1 and 2. Pass strain of $\Delta \varepsilon=0.8$ was employed. Pass by pass of MDF, the forging axis was changed by 90 degrees. About the MDF

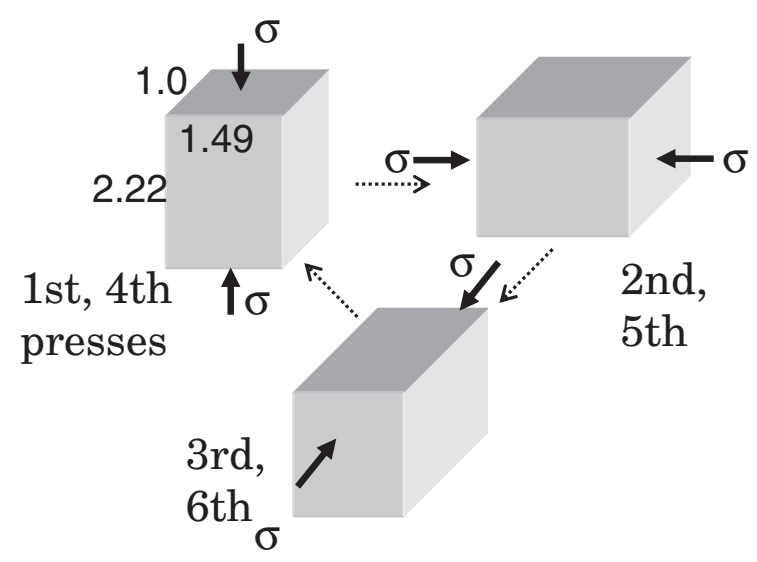

Fig. 1 A schematic representation of multi directional forging. Forging axis is changed by 90 degrees by each pass strain. At each 3 passes, the sample becomes to possess the same forging direction; $1 \mathrm{st}=4$ th.

method, it is precisely reported elsewhere. ${ }^{2)}$ After MDF followed by water quench, the evolved microstructure was observed on the plane parallel to the final forging axis using optical microscopy and transmission electron microscopy (TEM). The mechanical properties were investigated by the Vickers hardness test at room temperature and tensile test at temperatures from $473 \mathrm{~K}$ and $503 \mathrm{~K}$ at an initial strain rate of $8.3 \times 10^{-4} \mathrm{~s}^{-1}$. Tensile samples with gage size of $3 \times$ $0.6 \times 9 \mathrm{~mm}^{3}$ were discharge machined and tensile tested to the direction normal to the final forging axis of MDF. Some of the MDFed samples were annealed to investigate the thermal stability.

\section{Results and Discussion}

\subsection{Evolved microstructure}

The flow curves during MDF for the AZ31 and AZ61 Mg alloys are illustrated in Fig. 3. In the both alloys, the flow stress increases with decreasing temperature and increasing cumulative strain. Even after MDF of the AZ61 Mg alloy to 


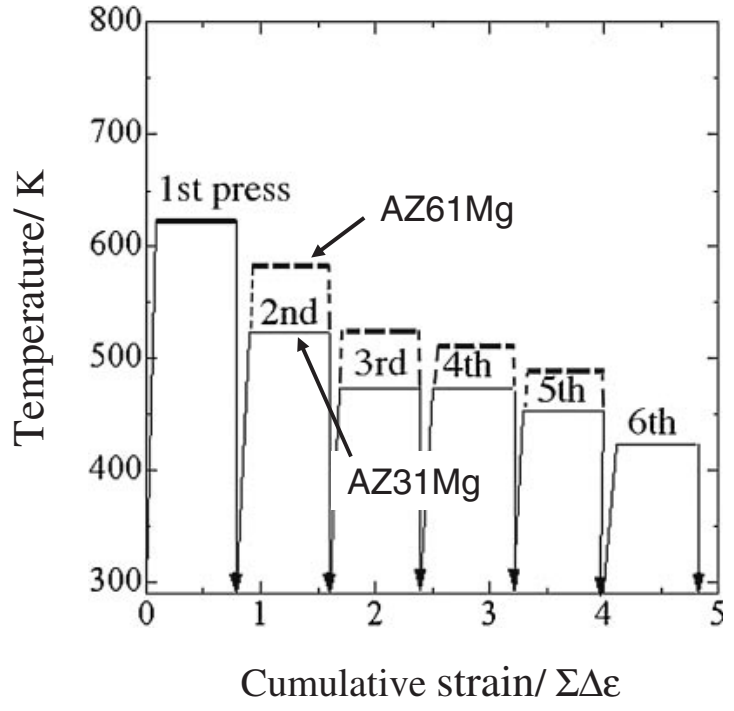

Fig. 2 The profiles of forging temperature v.s. cumulative strain during multi directional forging with decreasing temperature adopted to AZ31 and AZ61 Mg alloys. The thin solid and the bold broken lines indicate the processes for AZ31 and AZ61Mg alloys, respectively. Arrow marks indicate water quenching.

cumulative stain of $\Sigma \Delta \varepsilon=3.2$, the samples could be further uniformly deformed at temperatures between $463 \mathrm{~K}$ and $503 \mathrm{~K}$ without any cracking. When the coarse grained AZ31 $\mathrm{Mg}$ alloy $(\mathrm{d}=22.3 \mu \mathrm{m})$ was simply compressed at $473 \mathrm{~K}$, large cracks appeared before a strain of 0.2 (Fig. 3(b)). ${ }^{2}$ Therefore, it is evident that the obvious improvement of ductility of AZ61 Mg alloy by MDF shown in Fig. 4 is induced by uniform evolution of UFGs. In both alloys, stress peaks followed by large work softening appears at lower strain region. This phenomenon is mainly associated with strong $\left(\begin{array}{llll}0 & 0 & 0 & 1\end{array}\right)$ texture and crystal rotation during deformation. The sharper peak stresses followed by larger work softening appeared in the AZ61 Mg alloy in Fig. 4 would be presumably due to effects of stronger $\left(\begin{array}{llll}0 & 0 & 0 & 1\end{array}\right)$ texture evolution, restriction of non-basal slips and more frequent occurrence of deformation twins compared with those in the AZ31 Mg alloy. It is known that the role of GBS on ductility and flow stress becomes more important with decreasing grain size. ${ }^{2)}$ The disappearance of the sharp stress peaks at higher strain region in Fig. 3 should imply the more important role of GBS than slip deformation mechanism.

Microstructural change of AZ31 and AZ61 Mg alloys during MDF is shown in Fig. 4. It is apparent that the microstructure drastically changes by MDF. The grain size decreases significantly with increasing strain. At each MDF step, almost homogeneous microstructure could be obtained. After straining to $\Sigma \Delta \varepsilon=3.2$, the measured average grain size by using optical microscopy was about $1 \mu \mathrm{m}$ in both $\mathrm{Mg}$ alloys. The microstructure of the AZ61 Mg alloy at $\Sigma \Delta \varepsilon=3.2$, however, looks more uniform compared with that of AZ31 one. The microstructure of the AZ61 Mg alloy MDFed to $\Sigma \Delta \varepsilon=3.2$ was precisely investigated by means of TEM method and the photograph is exhibited in Fig. 5. It is evident from Fig. 5 that UFGs are uniformly evolved already at $\Sigma \Delta \varepsilon=3.2$. The average (sub)grain size was measured to be about $0.5 \mu \mathrm{m}$.

The change of grain size during MDF was investigated and the results are summarized in Fig. 6. It is clear in Fig. 6 that the average grain size simply decreased with increasing cumulative strain. The reduction of the grain size seems more obvious at the earlier stages of MDF. This would be induced by grain subdivision by mechanical twinning and kinking in addition to grain refinement by dynamic recrystallization (DRX) at higher temperature. The twinning, which appears more frequently in coarser grains, ${ }^{4,5)}$ therefore, can contribute to acceleration of uniform grain refinement even at quite low strain region. ${ }^{6,7)}$ On the other hand, the grain refinement at higher strain region and at lower temperature would be induced by mechanism of low temperature continuous dynamic recrystallization (cDRX), i.e., strain induced grain refinement. ${ }^{8}$ ) This will be discussed later. Because the reduction of the grain size appears not to be saturated in Fig. 6, it is expected that further grain refinement should be easily achieved. Xing et al. reported UFG evolution of about
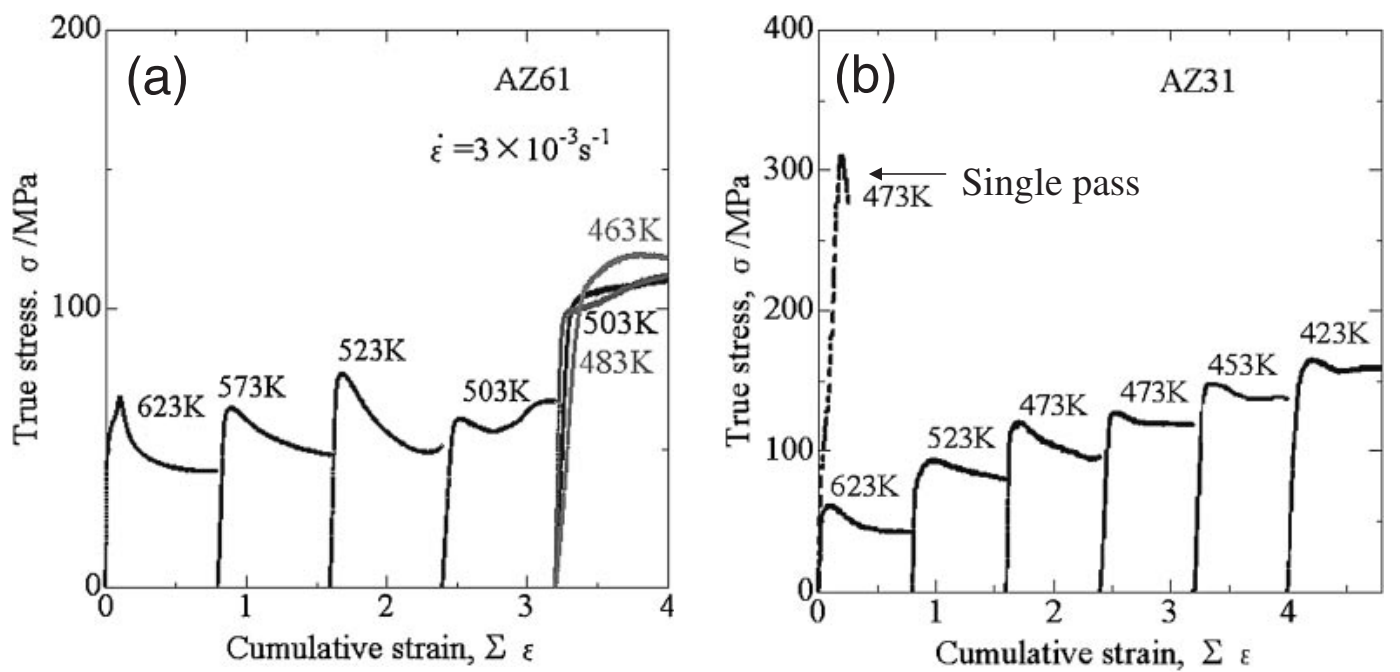

Fig. 3 True stress v.s. cumulative strain curves for (a) AZ61 Mg and (b) AZ31 (after Xing et al. ${ }^{2)}$ ) alloys. In the AZ31 Mg alloy, the flow curve obtained by single compression at $473 \mathrm{~K}$ is also exhibited. 

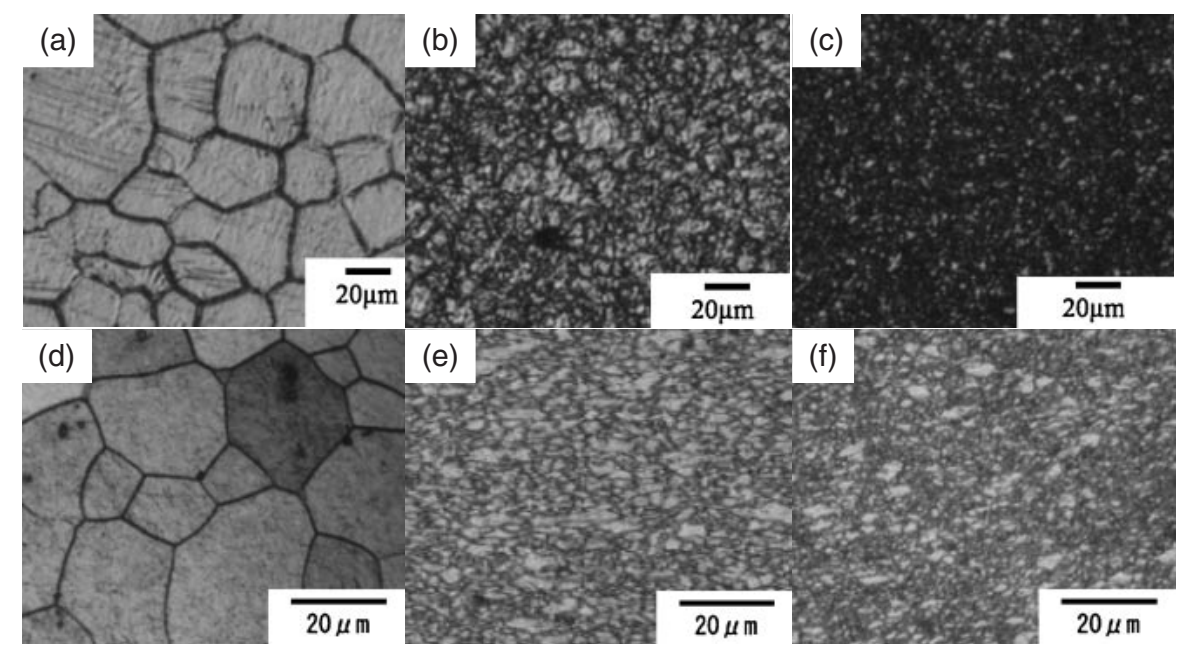

Fig. 4 Microstructure evolved by multi directional forging during decreasing temperature of AZ61 Mg alloy of (a) $\varepsilon=0$, (b) $\Sigma \Delta \varepsilon=1.6$,

(c) $\Sigma \Delta \varepsilon=3.2$, and of AZ31 Mg alloy ${ }^{2}$ of (d) $\varepsilon=0$, (e) $\Sigma \Delta \varepsilon=1.6$, (f) $\Sigma \Delta \varepsilon=3.2$.

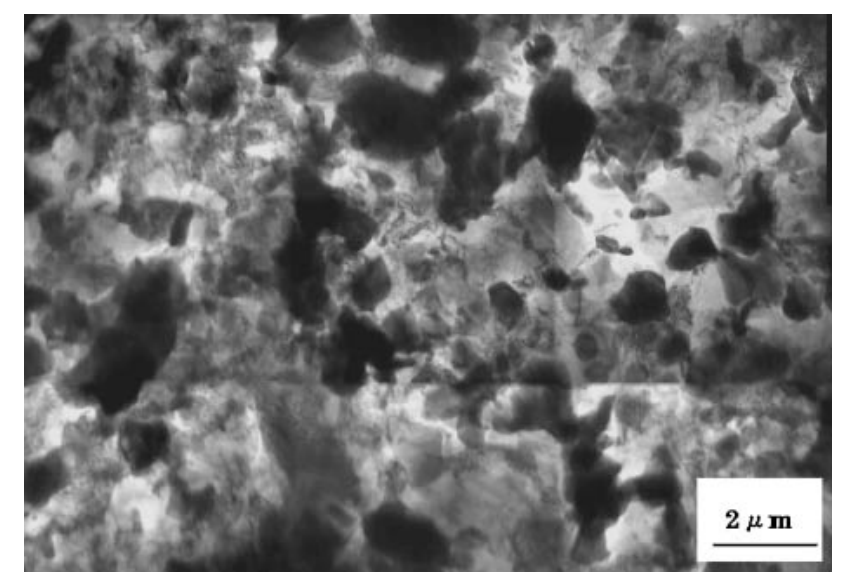

Fig. 5 A TEM photograph of the MDFed AZ61 Mg alloy to $\Sigma \Delta \varepsilon=3.2$.

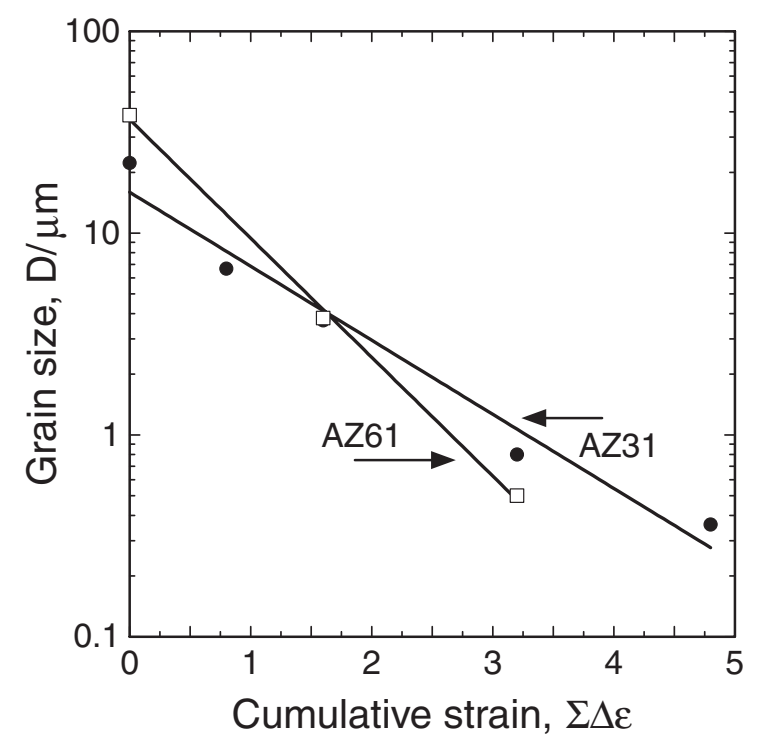

Fig. 6 Change of the average grain size depending on cumulative strain in the AZ31 and AZ61 Mg alloys processed by multi directional forging during decreasing temperature.
$0.35 \mu \mathrm{m}$ at $\Sigma \Delta \varepsilon=4.8$ in an AZ31 $\mathrm{Mg}$ alloy. ${ }^{2)}$ When compared the tendency of microstructural evolution, it in AZ61 Mg alloy appears more rapid, easy and uniform than that in AZ31 Mg alloy. From Figs. 3 and 6, it is confirmed that the observed large plasticity in the MDFed Mg alloys is, therefore, due to evolution of UFGs.

\subsection{Properties of the UFGed Mg alloys}

Hardness change with decreasing grain size was investigated at room temperature and the result is summarized in Fig. 7. The hardness increases monotonically with increasing cumulative strain. It is notable in Fig. 7 that increase in the hardness in the AZ61 Mg alloy is more significant than that in the AZ31 Mg one even while the AZ61 Mg alloy was MDFed rather higher temperatures. The AZ61 $\mathrm{Mg}$ alloy MDFed to $\Sigma \Delta \varepsilon=4.0$ exhibited hardness over $1.2 \mathrm{GPa}$, while that of the AZ31 $\mathrm{Mg}$ alloy was $850 \mathrm{MPa}$ at $\Sigma \Delta \varepsilon=4.8$. When deformed at higher temperature, the hardness becomes lower due to recovery and DRX. The significantly higher hardness in AZ61 Mg alloy than in AZ31 one in Fig. 7 must be induced by more rapid evolution of UFGs. When forged at lower temperature at the final step of MDF, at $483 \mathrm{~K}$ and $463 \mathrm{~K}$, the flow stress increased as already shown in Fig. 3. This would be brought by further grain refinement and higher dislocation density. In this case, hardness would be further raised. Of course, precipitation might affect the change of hardness. However, precipitation after quite short periods of keeping time for MDF at such high temperatures over $503 \mathrm{~K}$ would be difficult. In fact, no evidence of precipitation after forging at $503 \mathrm{~K}$ was confirmed by TEM observation in Fig. 5.

$\mathrm{Mg}$ and $\mathrm{Mg}$ alloys is traditionally assumed to exhibit continuous dynamic recrystallization (cDRX) behavior, when deformed at high temperature. Therefore, it has been believed that grain refinement during hot deformation is induced by the occurrence of cDRX. The enhanced grain refinement in $\mathrm{Mg}$ alloy during MDF as such observed in the present study must be, however, difficult only by a simple mechanism of cDRX. In case of a copper alloy MDFed, in which only mechanism of cDRX works, uniform evolution of 


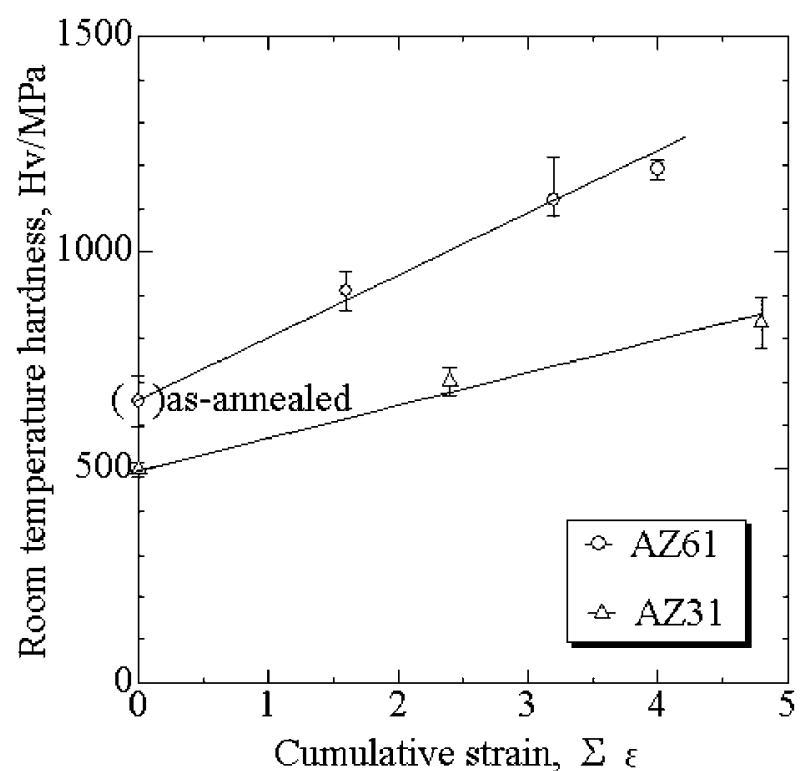

Fig. 7 Room temperature hardness change depending on cumulative strain in the AZ31 and $61 \mathrm{Mg}$ alloys processed by multi directional forging.

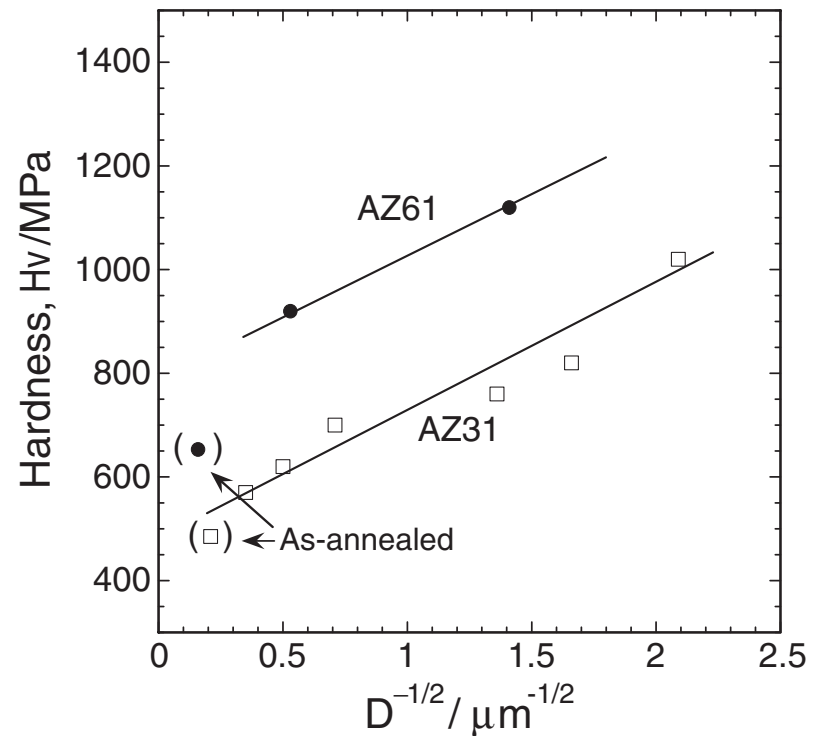

Fig. 8 Hall-Petch plot of the multi directionally forged AZ31 and $61 \mathrm{Mg}$ alloys.
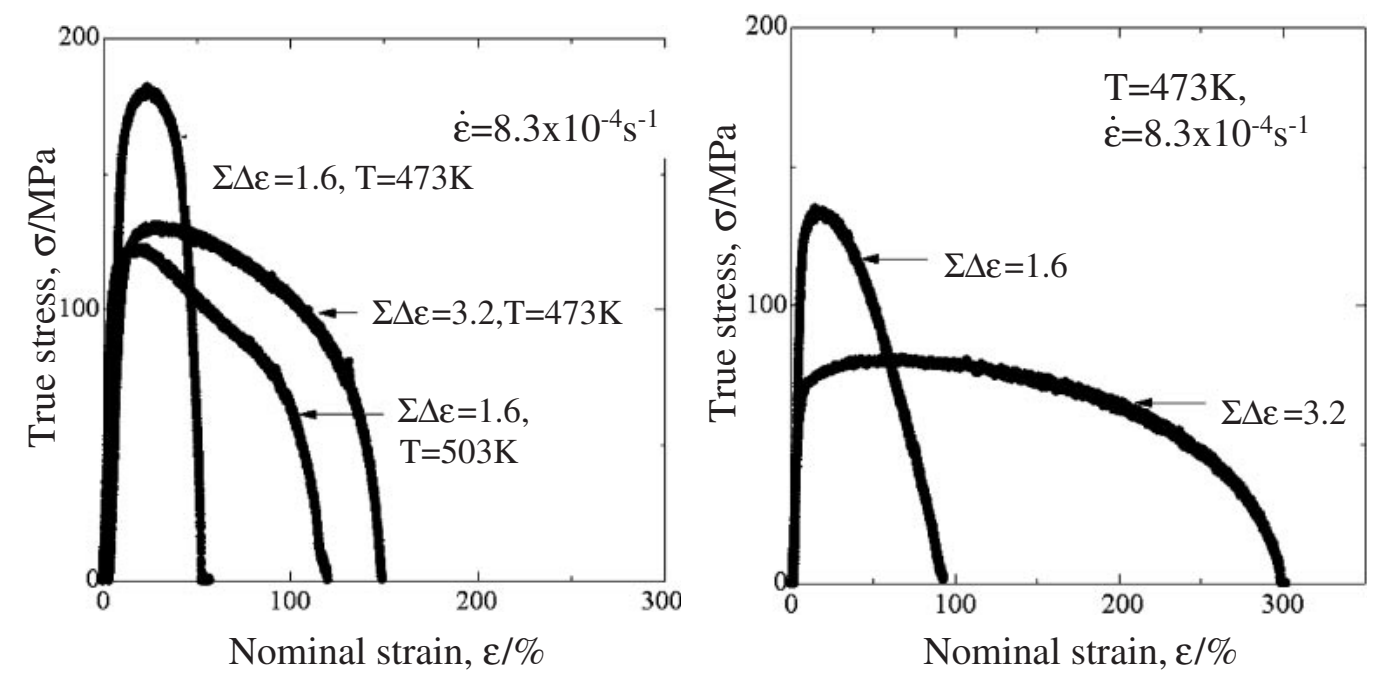

Fig. 9 True stress - nominal strain curves of the AZ61 Mg alloy multi directional forged to cumulative strains of $\Sigma \Delta \varepsilon=1.6$ and 3.2 .

UFGs could be achieved at rather higher cumulative strain over $\Sigma \Delta \varepsilon=6 .{ }^{9)}$ Recently, the important roles of kink ${ }^{5)}$ and mechanical twin ${ }^{6,7)}$ on the grain refinement in $\mathrm{Mg}$ and $\mathrm{Mg}$ alloys have been reported. The formation of kinks and deformation twins during high temperature deformation can accelerate subdivision of the initial grains. Kinking and twinning appear more actively either in the finer and coarser grains, respectively. The observed enhanced grain refinement would be, therefore, caused by the combined effects of kinking and deformation twinning in addition to the mechanism of cDRX at high temperature and at low strain regions. After sufficient grain refinement, the mechanism of low temperature cDRX, then, plays an important role for further grain refinement at lower temperature and at higher strain regions. $\mathrm{Mg}$ alloys, therefore, exhibits very complicated grain refinement manner during SPD strongly depending on grain size, temperature and etc.
The relation of grain size (D) and hardness at room temperature was summarized in Fig. 8. Although the number of data points of the AZ61 Mg alloy is not sufficient enough, it is roughly understood that the hardness increases proportionally to the value of $\mathrm{D}^{-1 / 2}$. This result indicates that HallPetch relation is hold down to the ultra fine grain region around $0.3 \mu \mathrm{m}$ even after severe plastic deformation in both alloys. Because all of the MDFed samples possess high density of dislocation, it is reasonable that the data points of the as-annealed samples are not on the lines.

MDFed AZ61 Mg alloy was tensile tested at elevated temperatures and the results are shown in Fig. 9. When tested at $473 \mathrm{~K}$, ductility increases as cumulative strain of MDF increases. That is, as grain size decreases, ductility is drastically improved. Especially when deformed at $473 \mathrm{~K}$ and at $8.3 \times 10^{-4} \mathrm{~s}^{-1}$, a large ductility of $300 \%$ was achieved. The observed such large ductility accompanied 
by low flow stress is due to occurrence of superplastic behavior, in which deformation is controlled by GBS. Xing et al. reported that superplasticity of $350 \%$ in nominal strain at maximum at $473 \mathrm{~K}$ and at $8.3 \times 10^{-5} \mathrm{~s}^{-1}$ was achieved in the AZ31 Mg alloy MDFed to $\Sigma \Delta \varepsilon=4.8 .^{2)}$ In the present study, however, almost comparable ductility was achieved in AZ61 $\mathrm{Mg}$ alloy at lower cumulative strain and at higher strain rate. This result would indicate that UFGed AZ61 $\mathrm{Mg}$ alloy possesses potential of much better ductility at elevated temperature. The fractured samples are exhibited in Fig. 10. It is notable to see that the area reduction drastically increased as the cumulative strain increased. This result suggests again improvement of plastic deformability by MDF and grain refinement.

It is known that SPDed metallic materials exhibit quite low thermal stability. Static recrystallization (SRX) occurs at much lower temperature in the SPDed materials than those of normal grain sized. ${ }^{9)}$ This is due to high stored strain energy and dislocation density. The thermal stability test of the AZ31 and AZ61 Mg alloys MDFed to $\Sigma \Delta \varepsilon=$ 3.2 was carried out at $473 \mathrm{~K}$. SRX and/or grain growth occurred almost whole area after annealing for $10^{3} \mathrm{~s}$ in the AZ31 Mg alloy (Fig. 11(b)). On the other hand, no microstructural change appeared in the AZ61 one after annealing at $473 \mathrm{~K}$ for $9 \times 10^{2} \mathrm{~s}$. Therefore, the AZ61 Mg alloy sample was further additionally annealed at $523 \mathrm{~K}$ for $9 \times 10^{2}$ s. Only a slight grain coarsening from $1 \mu \mathrm{m}$ to $2 \mu \mathrm{m}$ in average grain size appeared (Fig. 11(d)). It is already evident that AZ61 Mg alloy MDFed exhibits much better thermal stability than that of AZ31 one. This higher thermal stability might be introduced by higher element addition

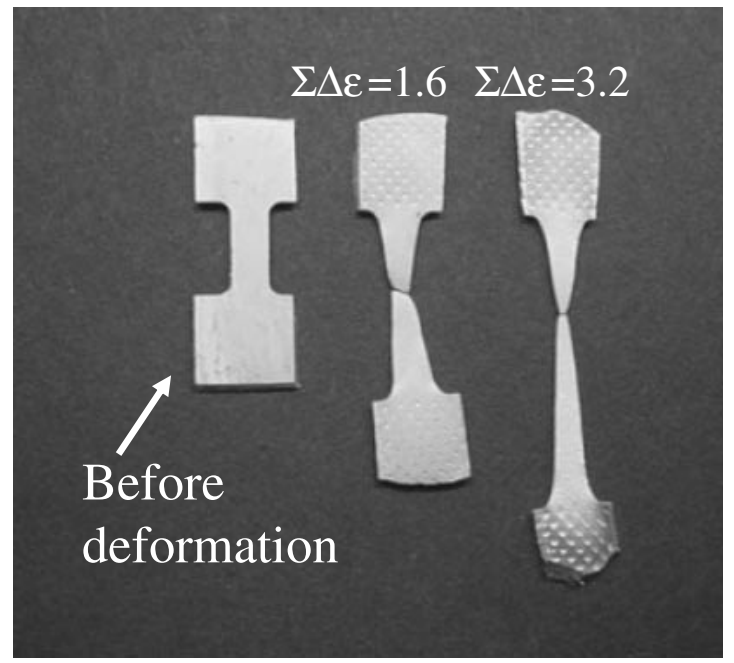

Fig. 10 Fractured samples of the AZ61 Mg alloy multi directionally forged to cumulative strains of $\Sigma \Delta \varepsilon=1.6$ and 3.2. Tensile test was carried out at $473 \mathrm{~K}$ and at $8.3 \times 10^{-4} \mathrm{~s}^{-1}$.

of aluminum and precipitation, while the latter was not actually observed. Further research is required to reveal why such differences of properties between AZ31 and AZ61 Mg alloys arose.

\section{Summary}

AZ61 Mg alloy was multi directionally forged (MDFed) during decreasing temperature to obtain ultra fine grains (UFGs). The tendency of grain refinement, mechanical

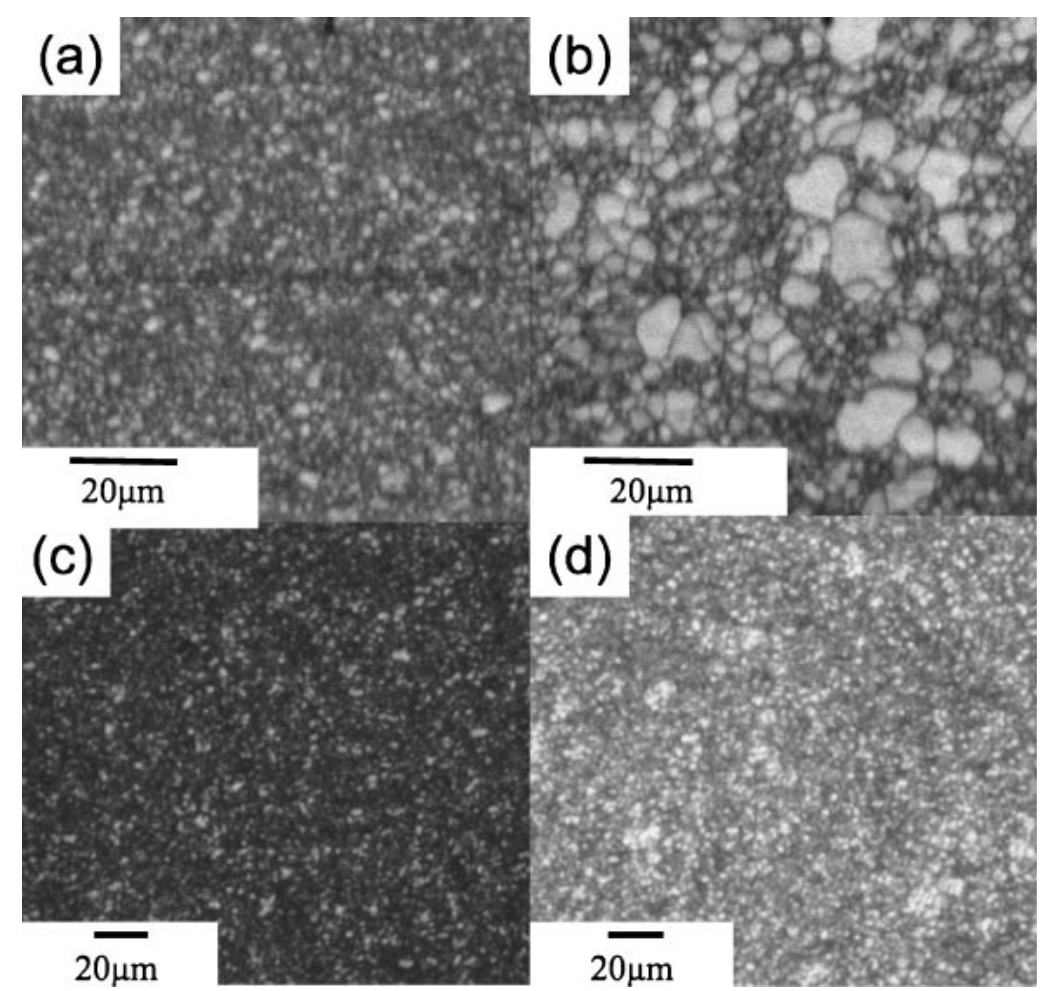

Fig. 11 Microstructural change by annealing test at $473 \mathrm{~K}$ for various periods of time of the AZ31 and AZ61 Mg alloys multi directionally forged (MDFed) to $\Sigma \Delta \varepsilon=3.2$ : AZ31Mg (a) as MDFed and (b) annealed at $473 \mathrm{~K}$ for $10^{3} \mathrm{~s}$, AZ61 Mg alloy (c) as MDFed and (d) annealed at $473 \mathrm{~K}$ for $9 \times 10^{2} \mathrm{~s}$ and further at $523 \mathrm{~K}$ for $9 \times 10^{2} \mathrm{~s}$. 
behaviors and thermal stability were compared with those of AZ31Mg alloy. The grain size decreased with increasing number of pass of MDF. However, tendency of the grain refinement appeared more accelerated or enhanced in the AZ61 Mg alloy than in the AZ31one. At cumulative strain of $\Sigma \Delta \varepsilon=3.2$, UFGs of about $0.5 \mu \mathrm{m}$ in diameter were uniformly evolved in AZ61 Mg alloy. In spite of the same grain size, AZ61 Mg alloy exhibited much higher strength and ductility compared with those of AZ31 Mg alloy. The thermal stability of the UFGed AZ61 alloy was much higher than that of the AZ31 $\mathrm{Mg}$ one.

\section{Acknowledgements}

The authors acknowledge the financial support given by the Light Metals Educational Foundation, Japan.

\section{REFERENCES}

1) Nanomaterials by severe plastic deformation, ed. by Z. Horita, (Trans Tech Publications 2005).

2) J. Xing, X. Yang, H. Miura and T. Sakai: Mater. Trans. 46 (2005) 16461650

3) J. Koike, R. Ohyama, T. Kobayashi, M. Suzuki and K. Maruyama: Mater. Trans. 44 (2003) 1-7.

4) M. R. Barnett, Z. Keshavarz, A. G. Beer and D. Atwell: Acta Mater. 52 (2004) 5093-5103.

5) X. Yang, M. Sanada, H. Miura and T. Sakai: Mater. Sci. Forum. 488-489 (2005) 223-226.

6) H. Miura, X. Yang, T. Sakai, H. Nogawa, S. Miura, Y. Watanabe and J. J. Jonas: Phil. Mag. 85 (2005) 3553-3565.

7) O. Stidikov and R. Kaibyshev: Mater. Trans. 42 (2001) 1928-1937.

8) T. Sakai, H. Miura, K. Usui and T. Koba: Proceedings of the 25th Risoe Inter. Symp. on Mater. Sci., Evolution of Deformation Microstructures in 3D, (2004), pp. 509-514.

9) H. Miura and T. Sakai: Proceedings of 2nd Inter. Symp. on "Ultrafine grained structure" (ISUGUS2), (Geelong, Australia), CDROM, (Inst. of Materials Engineering Australia Limited), (2004). 